\title{
AduLeT project: leading technology enhanced learning tips
}

\author{
Vitor Gonçalves $^{a}$, Isabel Chumbo ${ }^{b}$, Elisabete Mendes Silva ${ }^{c}$, Maria Raquel Patrício ${ }^{d}$ \\ ${ }^{a}$ Research Center in Basic Education, Instituto Politécnico de Bragança, Portugal, vg@ipb.pt. \\ bInstituto Politécnico de Bragança, Bragança, Portugal, ischumbo@ipb.pt. \\ 'Instituto Politécnico de Bragança, Bragança, Centro de Estudos Anglísticos da Universidade de \\ Lisboa, Portugal, esilva@ipb.pt. \\ ${ }^{\mathrm{d}}$ Research Center in Basic Education, Instituto Politécnico de Bragança, Portugal, raquel@ipb.pt.
}

\begin{abstract}
The European Commission favours the implementation and use of digital content and specially Open Educational Resources (OER) made accessible in higher education. Most of the lecturers have neither the skills nor the time to supply the teaching materials as digital content or OER. Therefore, Advanced Use of Learning Technologies in Higher Education (AduLeT) is a project that has been set up within the European Union Erasmus+ programme support, involving seven partners working together from November 2016 to August 2019. This project will provide lecturers with a community to share user experiences that integrate selected teaching methods with technologies and learning objects to solve an educational problem. AduLeT project brings in a Community of Practice (CoP) for lecturers with suitable teaching methods for technology enhanced learning (TEL). One specific requirement is the visualization of a set of category of tools matching with methods, like a matrix of methods and tools that can easily help teachers choosing from them. The lecturer can also find guidelines in the CoP for the effective use of TEL tools according to the methodology he/she plans to use in the learning process.The CoP will also make it possible to get in touch with other lecturers and to share experiences about teaching with TEL tools. In this contribution we will present the main requisites and functionalities implemented to provide the CoP, based on two workshops with the lecturers of the partner countries. We believe that this project could be an excellent support to the teacher, because it will present good practices for the use of appropriate educational technologies, properly conformed with teaching methods applicable to the resolution of problems, difficulties and requisites of common teaching.
\end{abstract}

Keywords: Technology enhanced learning, TEL teaching methods, TEL educational tools, Community of Practice. 


\section{Introduction}

In the last two decades, the number of lectures interested in promoting changes in pedagogical practices and integrating information and communication technologies in the teaching and learning process has been increasing.

As main objective, the European project AduLeT intends to offer an online platform that supports and fosters a community of practice for teachers of higher education so that they can share information and experiences of use of educational technologies in order to promote their advanced use by more teachers and educators in order to contribute to improving the quality, originality, innovation and variety of digital resources, as well as of the teaching and learning process in the context of higher education.

This project is co-funded by the Erasmus+ programme of the European Union, running from 01 November 2016 until 31 August 2019, and involves the following educational institutions: PH-Ludwigsburg University of Education (LUE, Alemanha), University of Stuttgart (US, Alemanha), Universidad Complutense de Madrid (UCM, Espanha), Humak University of Applied Sciences (Humak, Finlândia), University Johanes Neumann (PAE, Hungria), Open Universiteit Nederland (OUNL, Holanda), Instituto Politécnico de Bragança (IPB, Portugal) and International Education and Training Institution (Pixel, Itália).

Higher education teachers can consult or contribute with their experiences of using technology-assisted learning or Technology Enhanced Learning (TEL). Therefore, like we summarize in our AduLeT Website (2016), with the AduLeT platform (the community of practice platform) any lecturer can add/consult: TEL Teaching Methods, TEL Tools, TEL Problems, and particularly TEL User eXperiences.

In short, the purpose of this paper is, first, to present the project, the consortium and the main results, and then, describe the main functionalities of the AduLeT platform, noting the importance of the two "build the community" workshops that allowed, at an earlier phase, to identify and specify requirements, and then test and validate the interfaces and functionality of the Community of Practice (CoP) platform.

\section{The AduLet project}

According to Wenger, McDermott, \& Snyder (2002, p. 3) "Companies at the forefront of the knowledge economy are succeeding on the basis of communities of practice, whatever they call them". Taking into account this statement, one verifies that the concept and functionality of Communities of practice are overwhelmingly valid and relevant nowadays. As such, this statement supports the overall idea of the AduLet project framed on a CoP. 
The mission of this project is indeed to create and stimulate a community of practice where higher education teachers can identify and share their experience(s) of using teaching and learning methods and corresponding educational technologies.

To that end, after having analysed a set of studies and research methods and identified the main known barriers (time, motivation, institutional and cultural factors, self-efficiency / self-confidence), the consortium has been working on the basis of the main results (Fig. 1): 1) Teaching Methods TEL; 2) TEL tools; 3) Case Studies; 4) Survey; 5) Community of Practice.

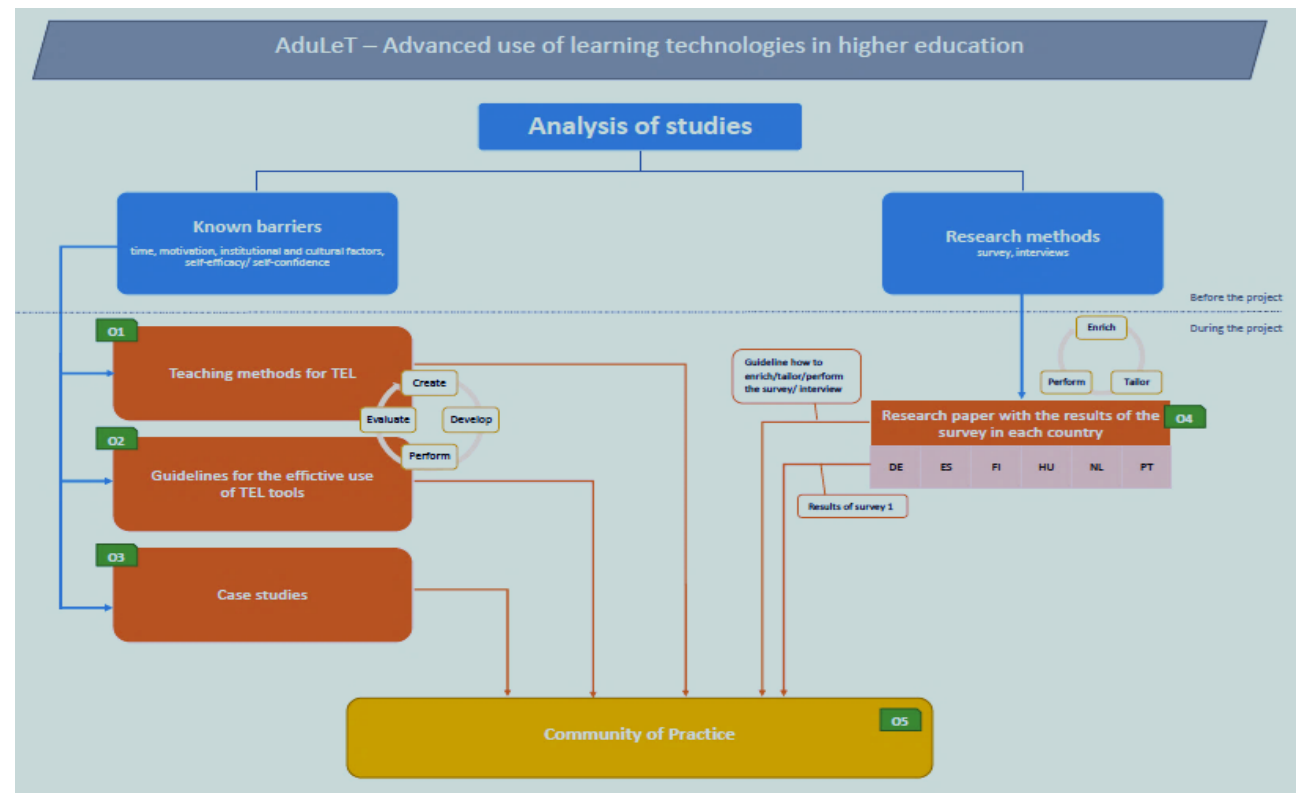

Fig. 1 AduLeT - The big picture (Adulet Consortium, 2017).

The consortium, by itself, constitutes a community of practice that communicates online using tools such as: Google Drive, Adobe Connect, Facebook page and WhatsApp group.

Communities of Practice are groups of people who share a concern, a set of problems, or a passion about a topic, and who deepen their knowledge and expertise in this area by interacting on an ongoing basis (Wenger et al., 2002, p. 4).

Communities of practice are not new and are present everywhere. Since knowledge is one of the main keys to success in the information and knowledge society in which we live, then communities of practice are the crucial tool for connecting people and consequently building and disseminating knowledge.

Thus, in this online community of practice, a teacher can add/consult: teaching and learning methods that can be assisted by technologies, educational technologies appropriate to 
particular teaching and learning method(s), problems or situations in the learning process that can be solved or minimized using a method/tool pair, and specifically usage reports of that method/tool combination, which relates a method to a technology in order to add or consult the description of the experiment or the guidelines for the effective use of a given educational technology.

Given the pedagogical, cultural and linguistic differences in the consortium, we can say that one of the main initial challenges was to reach agreement on a common vision regarding educational methods and tools. In an attempt to congregate the main visions in the consortium regarding the definitions of teaching method and tools, the AduLeT consortium proposed an objective and straightforward and far-reaching definition. A teaching method is a logical process through which knowledge is obtained. It is organised in a succession of logical steps or stages aiming at achieving (a) predetermined goal(s). In what we believe to be a widening scope, a teaching method comprises a set of methodologies, strategies and techniques, tools and learning activities (Fig. 2).

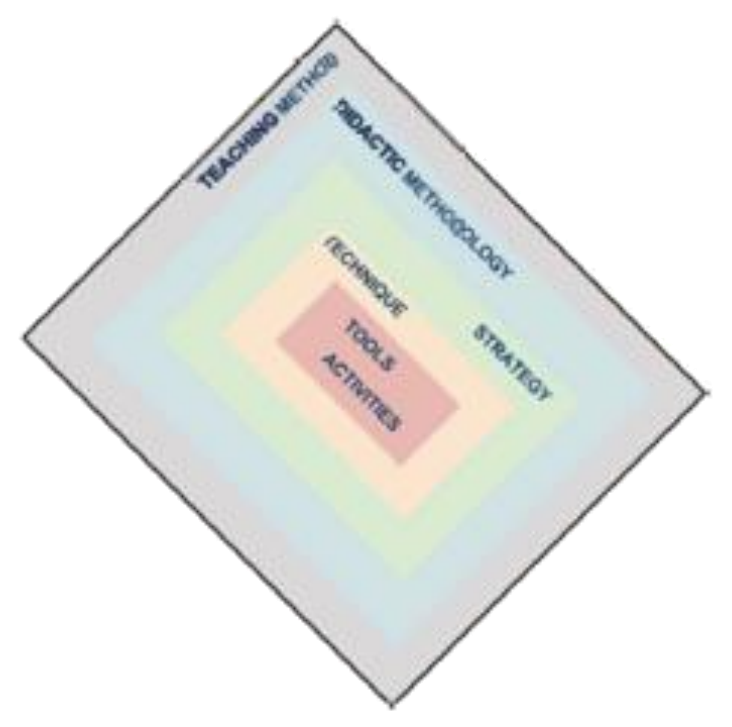

Fig. 2 AduLeT-Teaching Method and Tool in AduLeT project.

A Tool is a set of instruments, either technological or didactic, used to perform a particular task/activity. E.g. A coursebook (a tool but also a learning object itself), either digital or paperback, has several learning objects (contents and tasks/activities). A platform like Moodle is the technological tool and the coursebook (in Moodle, for example), is a didactic tool, however with different levels of granularity. Summing up, paper is the same as Moodle, though in different layouts. 
After this first task, the second main task was the development of templates that would allow the collection of teaching methods and appropriate tools. In addition to the preparation of the first templates for the teaching methods and for the TEL tools, the concepts for the communication plan with information about meetings, staff and organisation of meetings and for the build the community workshops were also defined.

To discover the main problems, five experts from each partner were invited to use the Group Concept Mapping (https://conceptsystemsglobal.com). The use of this system was cropped up in two phases: i) the Brainstorming phase occured by the end of 2017 and the experts identified the main statements that represent major constraints to the use of technologies; ii) the Classification of statements phase occured in the beginning of 2018 and the experts contributed to the sorting of statements. In brief, the most important identified statements were: lack of support from organisation; teachers' lack of knowledge and skills; lack of time; lack of hardware and software; students' lack of knowledge, skills and motivation and lack of reward and recognition. These statements have been compared on importance vs Easy/Difficult to solve and in a general point of view justify the necessity of a CoP that can minimize those problems.

After, to plan the CoP and to collect the requirements which came up from the influencing intellectual outputs $(\mathrm{O} 1, \mathrm{O} 2$ and $\mathrm{O} 3)$, we had to define the platform to create the CoP. At first the AduLeT team had a closer look at existing systems like Wikis, GoogleSites, CRM and shopping systems, Moodle and Moodlerooms, WordPress or Joomla. Quickly the AduLeT team realized that the requirements of the CoP are very peculiar and therefore decided to involve more technical experts to the process of finding a proper basis for the CoP. The first proposal for developing this platform was settled on: open source PHP framework Yii2, open source Apache HTTP Web server, and MySQL database engine. But after testing the solution, the AduLeT team decided to use Drupal to create the first version of the $\mathrm{CoP}$.

About the build the community workshops, we have organized two different workshops in each partner instituition.

\section{The AduLet "build the community" workshops}

The main goal of the first workshop (July 2017) was to identify the requisites of the CoP and the main purpose of the second (June 2018) was to test the CoP platform that has been developed so far.

The first "build the community" workshop focused on the following content: i) Present the AduLeT-project (PPT) and hand out the project booklet; ii) Present the Teaching Method

Template and gather feedback/improvements from the lecturers; iii) Present the TEL-Tool 
Template and collect feedback/improvements from the lecturers; iv) Present the Grid and collect feedback/improvements from the lecturers; v) Brainstorming: further Teaching Methods; vi) Brainstorming: further TEL Tools; vi) Follow up: Who would like to try out which Teaching Methods and TEL tools to use in their teaching? More than 80 lecturers participated in this first "build the community" workshop that was held at all six universities of the project. In the Polytechnic Institute of Bragança (IPB), Portugal, the Adulet Workshop I took place in July 2017. The workshop was widely disseminated to all the teachers in the IPB. Despite several professional attendance constraints, 35 teachers attended the workshop in IPB. The lecturers had either already some experience in using technologies in their teaching or they had no experience whatsoever, but were interested in using technologies in their teaching. In all partners's institutions, during the workshops, the project AduLeT was introduced and presented. After that the template for the teaching methods and the template for the TEL tools were introduced and, more importantly, the lecturers had the possibility to give feedback concerning the structure and usability. In this way they were able to contribute to the revision of the templates for describing teaching methods and TEL tools. In a brainstorming session, specific teaching methods and TEL tools were collected. As a result, more than 40 teaching methods were described and suggested for the collection of teaching methods and more than 35 tools for the collection of TEL tools. Finally, the CoP platform was discussed and the lecturers could give feedback for the implementation of this community.

Based on the results of the first workshop, we were able to develop the platform to support the community of practice that was being created in the different countries of the consortium.

The second "build the community" workshop had as main purpose the evaluation of the usability, accessibility and functionalities of AduLeT CoP (http://dev.adulet.pt) and more than 60 lecturers participated in all six universities of the project. In Portugal, on June 22, 2018, the second "Build the Community Workshop" was held at the Polytechnic Institute of Bragança in which 18 teachers from the 5 schools of the IPB (2 hours) were present. As already mentioned, several professional tasks constrained the attendance of other colleagues. Therefore, a second dissemination session was held on June 27, 2018 for 10 teachers more (it lasted 1 hour). The workshop was mainly hands-on based aiming to obtain feedback from the participants about the CoP platform to test it. After a brief presentation of the Adulet project and the partner universities, the participants were asked to test the CoP platform by following the different steps contained in the comments to the community of practice form, a handout provided in the beginning of the session. While the participants were testing the $\mathrm{CoP}$ platform they identified problems and suggested improvements. Finally, they filled in the online final evaluation form. The participants gave a valuable 
contribution to the improvement of the $\mathrm{CoP}$ which is noticeable in the online creation of teaching methods, tools, problems and suggestions and through the evaluation form.

\section{The AduLet CoP platform}

The CoP platform provides access to all AduLeT outcomes: teaching methods, TEL tools, Problems and user eXperiences that can be searched, easily accessed, and even with some guidelines.

The CoP platform has been developed in constant interaction with current or potential users, in order to present information in a simple, user-friendly and intelligible way (Figs. $3,4,5$ and 6). This platform will provide the contact with other teachers, sharing experiences on the use of certain proposed tools as more suitable for certain methods.

\section{Adulet}

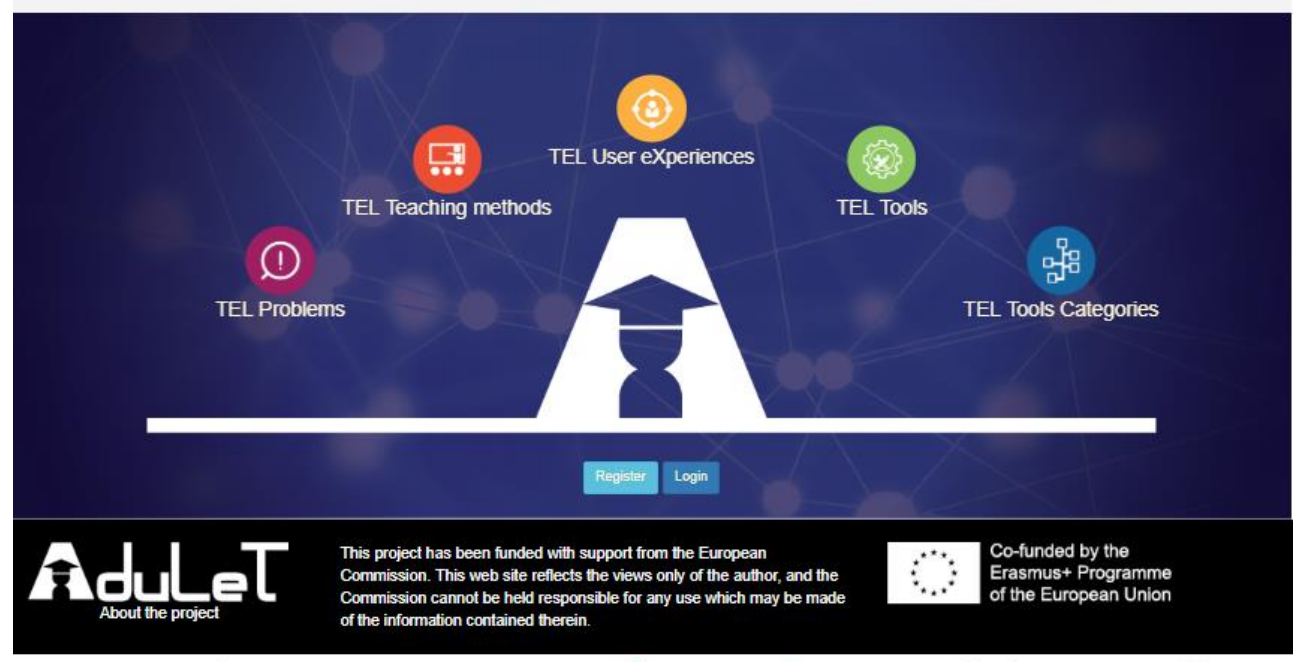

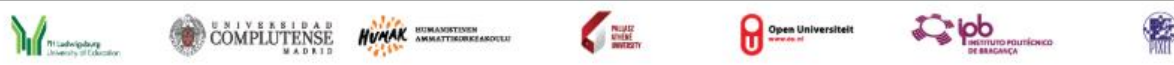

Fig. 3 AduLeT CoP Platform (Adulet platform, 2018). 


\section{Adulet}

TEL User eXperiences TEL Problems TEL Teaching Methods TEL Tools Register Log in

\section{User eXperiences}

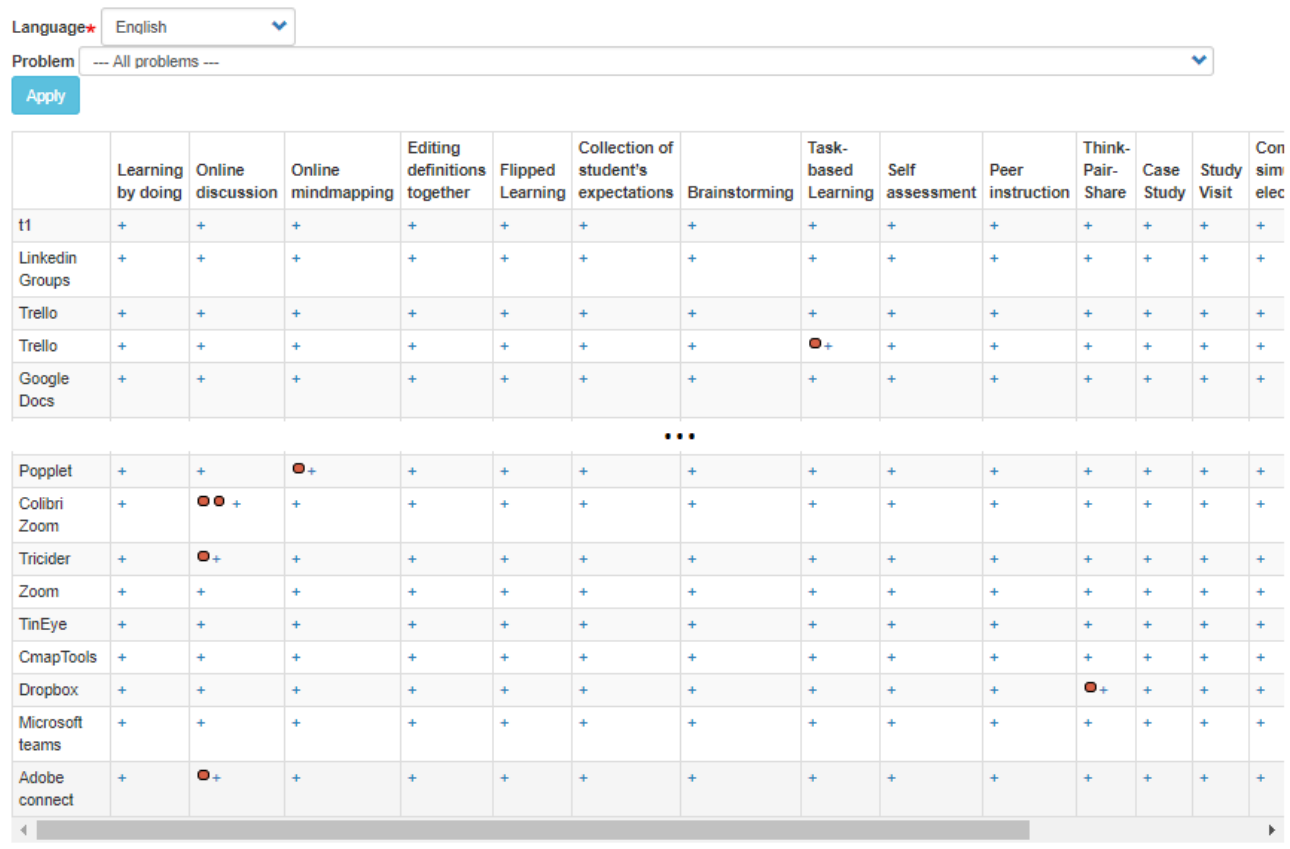

\section{ÂduLT}

This project has been funded with support from the European Commission. This web site reflects the views only of the author, and the Commission cannot be held responsible for any use which may be made of the information contained therein.

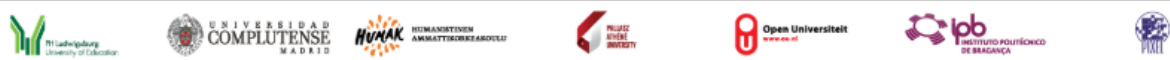

Fig. 4 AduLeT CoP Platform-TEL user eXperiences. 


\section{Adulet}

TEL User experiences TEL Problems TEL Teaching Methods TEL Tools Administration Register Log out

\section{TEL Teaching Methods}

\section{Create new TEL. Teaching Method}

Language* Enqlish
Subject - Any -
Duration - - Any -
Assessment method

\begin{tabular}{|c|c|c|}
\hline Title & & Operations \\
\hline Computer aided design (CAD) & translate & delete edit \\
\hline Gamificación (gamification) & transiate & delete edit \\
\hline e-portfolio & translate & dekete edit \\
\hline Learning by doing & translate & delete edit \\
\hline Guided design & transiate & delete edit \\
\hline reflective journal & transiate & delete edit \\
\hline Technology-enhanced CBL (Content-based Learning) & translate & delete edit \\
\hline Computer-based jigsaw learning & translate & delete edith \\
\hline Flipped Learning & transiate & delete edit \\
\hline
\end{tabular}

Fig. 5 AduLeT CoP Platform - TEL teaching methods.

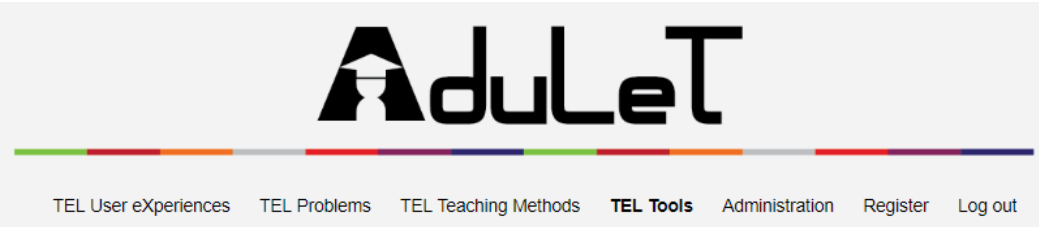

Tools

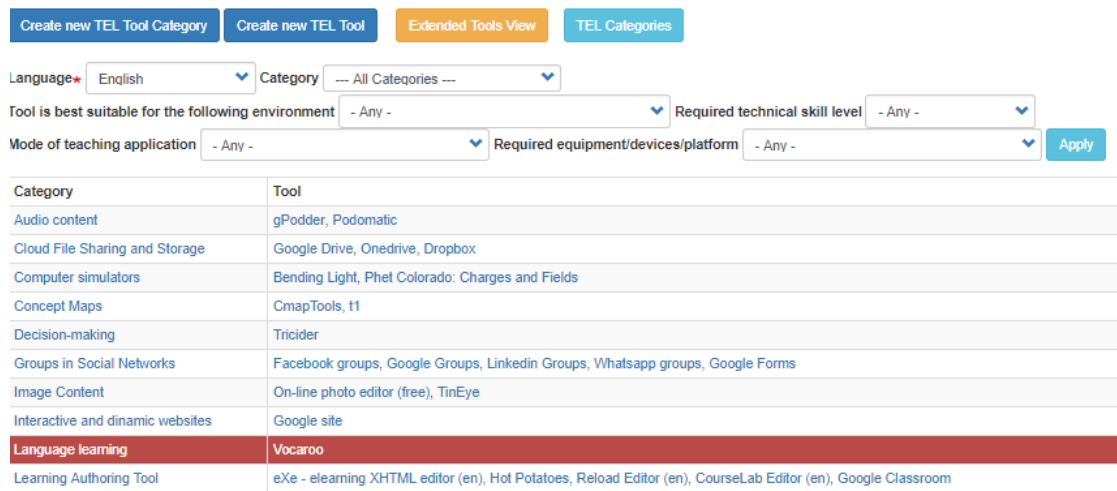

Fig. 6 AduLeT CoP Platform - TEL tools. 
The main functionalities of the CoP platform are:

- $\quad$ Repository of Teaching methods: a teacher can add or read a teaching method;

- $\quad$ Repository of TEL tools: a teacher can add or read a TEL tool;

- Repository of Problems: a teacher can add problems or situations to solve;

- Repository of User eXperiences: a teacher can add or read a user eXperience that crosses a teaching method with a TEL tool to solve a given problem.

\section{Conclusions}

The present time requires teachers to be able to know how to use educational technologies, to understand how they can use them to obtain a satisfactory result in the classroom. But, such use in the classroom should derive from the suitability of a given technology for the implementation of a particular method in a given context. The NMC Horizon Report: 2017 Higher Education Edition states that "Technology and digital tools have become ubiquitous, but they can be ineffective or dangerous when they are not integrated into the learning process in meaningful ways" (Adams Becker, Cummins, Davis, Freeman, Hall Giesinger and Ananthanarayanan, 2017, p. 7).

In this context, the AduLeT CoP can make a difference to lecturers' teaching practice by providing opportunities for technology enhanced learning. The advantage of this project is based on the involvement of several lecturers in the "build the community" workshops who, with their valuable contribution, help us to continuously update the platform for the benefit of everyone involved in the teaching-learning process.

We believe AduLeT CoP can help lecturers not only to improve teaching quality, but also to build connections, share experiences and collaborate efficiently by enhancing their skills in the use of advanced technologies. Consequently, AduLet CoP will be more open, global, collaborative and closer to Europe's Higher Education systems, and thus contribute to the innovation of education and training.

\section{Acknowledgements}

AduLeT has been funded with the support of the European Commission and co-funded by the Erasmus+ Programme of the European Union.

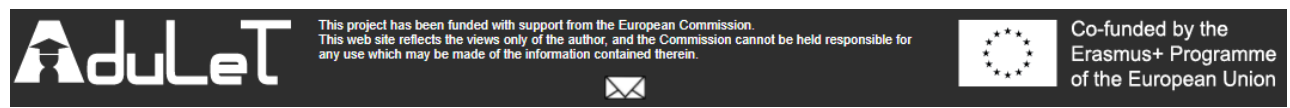




\section{References}

Adams Becker, S., Cummins, M., Davis, A., Freeman, A., Hall Giesinger, C., \& Ananthanarayanan, V. (2017). NMC Horizon Report: 2017 Higher Education Edition. Austin, Texas: The New Media Consortium.

Adulet Consortium (2017). Booklet AduLeT - Advanced use of Learning Technologies in Higher Education. Ludwigsburg: LUE.

Adulet Consortium (2016). Application Form KA2 - Cooperation for Innovation and the Exchange of Good Practices, Strategic Partnerships for higher education. Ludwigsburg: LUE.

Adulet Website (2017). Current work at the community of practice (CoP). URL: http://www.adulet.eu.

Adulet CoP Platform (2017). AduLeT Community of Practice. URL: http://dev.adulet.eu.

Gonçalves, V., Chumbo, I., Silva, E. M. \& Patrício, M. R. (2017). Advanced use of Learning Technologies in Higher Education: AduLeT Project big picture. In V Encontro de Jovens Investigadores. IP Bragança.

Gonçalves, V., Chumbo, I., Silva, E. M. \& Patrício, M. (2017). Apresentação AduLeT. In Workshop - Métodos inovadores de aprendizagem para promover as capacidades científicas dos alunos. Bragança: IPB.

Wenger, E., McDermott, R. \& Snyder, W.M. (2002). Cultivating Communities of Practice: A Guide to Managing Knowledge. Boston: Harvard Business Press. 